\title{
HÉLADE: PRIMEIRO TRIÊNIO DA NOVA SÉRIE
}

\begin{abstract}
Alexandre Santos de Moraes ${ }^{1}$
Thaís Rodrigues dos Santos ${ }^{2}$
\end{abstract}

Passaram-se três anos desde 2015, quando decidimos pelo retorno da Hélade, e estivemos diante de três desafios interdependentes. Em primeiro lugar, nosso objetivo era resgatar o conteúdo da série original que, por força do tempo e das circunstâncias, encontrava-se bastante disperso e, em parte, inacessível. Esse esforço devolveu à comunidade acadêmica um total de 48 artigos completamente reeditados. Em segundo lugar, em constância com essa disposição, buscamos recuperar a história da revista, as iniciativas que caracterizaram sua série inicial e os princípios editoriais da primeira revista eletrônica brasileira exclusivamente dedicada aos estudos da Antiguidade. Finalmente, em terceiro lugar, concentramos nossas energias para consolidar a Hélade como um espaço isonômico de publicação, amplo, receptivo e democrático, aberto a pesquisadoras e pesquisadores do Brasil e do exterior. Com esse número, chegamos ao primeiro triênio da nova série, período razoavelmente seguro para lançar um olhar retrospectivo e fazer um balanço dessa nova fase da revista.

Ao longo desses três anos, foram publicados oito números: dois em 2015, três em 2016 e outros três em 2017. A mudança na periodicidade tem a ver com a generosa acolhida da revista junto aos especialistas e o correspondente apoio de pareceristas ad hoc que asseguraram não apenas a viabilidade do sistema de avaliação às cegas, mas também a melhoria significativa dos

1 Professor do Departamento de História e do Programa de Pós-graduação em História (PPGH) da Universidade Federal Fluminense. Membro do Núcleo de Estudos de Representações e de Imagens da Antiguidade (NEREIDA/UFF) e colaborador do Laboratório de História Antiga (LHIA/UFRJ). Editor da Hélade.

2 Mestranda do Programa de Pós-graduação em História da Universidade Federal Fluminense (PPGH/UFF). Membra do Núcleo de Estudos de Representações e de Imagens da Antiguidade (NEREIDA/UFF). Assistente editorial da Hélade. 
trabalhos após as críticas e sugestões pertinentes. A opção pela publicação de dossiês ${ }^{3}$ estimulou diversas reflexões acerca de temáticas prementes do nosso presente, referendando não apenas o fato de que toda História é, por princípio, contemporânea, mas também que a Antiguidade é um locus privilegiado para refletirmos sobre nossos dilemas e conflitos. Os números que sintetizam esse trabalho são bastante elucidativos: foram publicados até o momento um total de 67 artigos, o que assegura uma média de pouco mais de 8 artigos por número.

Desde o início, a revista buscou garantir a ampla participação de especialistas que se dedicam ao estudo da Antiguidade. Uma vez que os artigos são avaliados pelo sistema "duplo-cego", os editores partiram da premissa de que a qualidade estava antes associada ao mérito dos trabalhos do que pura e simplesmente à titulação. Nesse sentido, ao longo desses três anos, acolhemos com entusiasmo artigos assinados por mestres, doutorandos e doutores ${ }^{4}$, contrariando a lógica do doutoramento obrigatório comumente adotado como critério nas avaliações. Outrossim, como indicam os números, 68,2\% dos artigos foram enviados por especialistas com doutorado 5 (45 no total) e $31,8 \%$ por mestres (22 no total). Trata-se, em certa medida, de uma proporção esperada, tendo em vista que é usual acumular mais debates e reflexões à medida que possuímos mais tempo dedicado às pesquisas. Outrossim, a participação de pesquisadores em estágios iniciais de formação também foi assegurada através de artigos em coautoria. Do total, 56 artigos (83,3\%) foram assinados individualmente e $11(16,6 \%)$ em coautoria. Ao longo do triênio, a Hélade contou a participação de 70 autores; desses, apenas 6 (8,7\%) assinaram mais de um artigo.

\footnotetext{
3 O primeiro número da nova série (v. 1, n. 1) foi uma edição especial em que convidamos autores da primeira série da revista a revisitarem os temas publicados há 15 anos. Em seguida, publicamos dossiês com os seguintes títulos: Literatura Antiga: Tempo e Tradiçâao (v. 1, n. 2); Jogos, Desporto e Práticas Corporais na Antiguidade (v. 2, n. 1); Religiões no Mundo Antigo (v.2, n. 2); Homoerotismo na Antiguidade (v. 2, n. 3); Golpes e Formas de Resistência na Antiguidade (v. 3, n. 1) e Etnicidade e as Políticas das Identidades nas Sociedades Antigas (v. 3, n. 2).

4 Além de graduandos, graduados e mestrados, desde que em coautoria com doutores, como indicado em nossas normas de publicação (http://www.helade.uff.br/normas.html).
}

5 Incluindo os artigos em coautoria e, nesse caso, considerando a titulação máxima de um dos autores. 


\section{Formação/titulação dos autores}

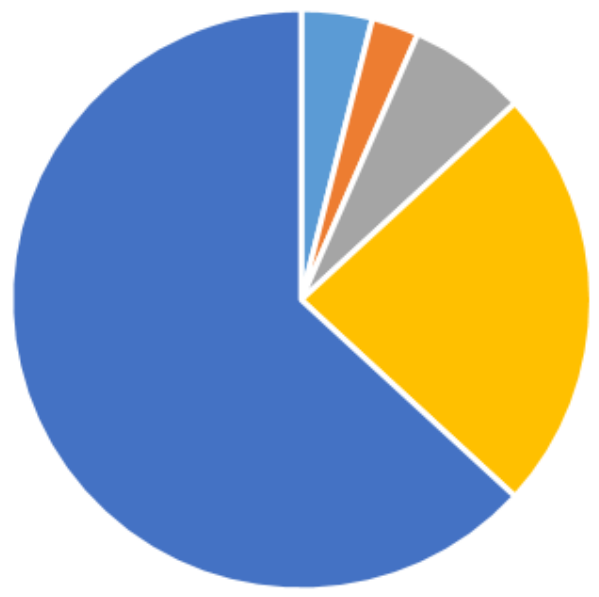

- Graduando(a) = Mestrando(a) - Mestre " Doutorando(a) - Doutor(a)

A diversidade teórico-metodológica foi assegurada pela ampla participação de pesquisadores e pesquisadoras de História, Letras, Psicologia, Filosofia e Arqueologia. A pluralidade de temas também ficou marcada por artigos que versavam sobre questóes associadas à Antiguidade Clássica, ao Antigo Oriente Próximo e ao Ensino de História. Em relação à origem institucional dos autores, os números indicam uma crescente ampliação do escopo da revista e a recusa intransigente a qualquer possibilidade de endogenia. A maioria dos participantes está vinculada a universidades brasileiras ${ }^{6}(80,3 \%)$,

6 Lista de universidades brasileiras participantes: Universidade Regional de Blumenau (FURB), Universidade do Estado do Amapá (UEAP), Universidade Estadual do Maranhão (UEMA), Universidade Estadual do Rio de Janeiro (UERJ), Universidade Federal do Espírito Santo (UFES), Universidade Federal Fluminense (UFF), Universidade Federal de Goiás (UFG), Universidade Federal de Minas Gerais (UFMG), Universidade Federal de Ouro Preto (UFOP), Universidade Federal de Pernambuco (UFPE), Universidade Federal do Paraná (UFPR), Universidade Federal do Recôncavo da Bahia (UFRB), Universidade Federal do Rio de Janeiro (UFRJ), Universidade Federal do Rio Grande do Norte (UFRN), Universidade Federal de Santa Catarina (UFSC), Universidade de Brasília (UnB), Universidade Estadual de Campinas (UNICAMP), Universidade Federal de São Paulo (UNIFESP), Universidade Federal do Estado do Rio de Janeiro (UNIRIO) e Universidade de São Paulo (USP). 
mas a diversidade institucional dos autores estrangeiros ${ }^{7}$ (19,7\% do total) sinaliza uma tendência bastante significativa de internacionalização da Hélade. No total, foram vinte universidades brasileiras e dez universidades estrangeiras representadas por seus autores ao longo desse primeiro triênio.

A preocupação com a divulgação dos trabalhos também marcou e consolidou a participação ativa da Hélade nas redes sociais, em particular no Facebook (https://www.facebook.com/revistaheladeuff/). Atualmente, nessa rede social, 4.755 usuários acompanham nossas publicações. Além de replicarmos notícias relativas à Antiguidade, divulgarmos a abertura de concursos públicos, entrevistas, lançamentos editoriais e números de revistas também dedicadas ao estudo do mundo antigo, a divulgação dos dossiês aproximou a História Antiga de um público muitas vezes privado do acesso à produção acadêmica pela forma com que nosso campo se estrutura. $\mathrm{O}$ índice de alcance das publicações é um poderoso indicativo desse movimento. O último dossiê publicado, Etnicidade e as Políticas das Identidades nas Sociedades Antigas (v. 3, n. 2), teve um alcance de 36.272 pessoas. Número, decerto, bastante expressivo, mas em nada equiparado ao de temáticas que dialogam diretamente com questóes políticas em que estamos diretamente envolvidos no presente da vida social. O dossiê Golpes e Formas de Resistência na Antiguidade (v. 3, n. 1), por exemplo, atingiu 51.116 pessoas, menos da metade das 127.540 pessoas alcançadas pelo dossiê Homoerotismo na Antiguidade (v. 2, n. 3). Esta atuação através das redes sociais será ampliada no início de 2018 com a construção de uma página no Academia.edu.

A Hélade é resultado do envolvimento coletivo dos membros do Núcleo de Estudos de Representações e de Imagens da Antiguidade (NEREIDA), vinculado ao Departamento de História e ao Programa de Pós-graduação em História (PPGH) da Universidade Federal Fluminense (UFF). Trata-se de uma iniciativa somente possível no marco de um trabalho em equipe que envolve editores, assistentes de edição, conselho editorial e conselho consultivo. O crescimento e consolidação da Hélade também é a expressão do suporte assegurado pela universidade pública e pelo trabalho que busca recrudescer seu caráter democrático, assegurando o compromisso com uma instituição que

7 Lista de universidades estrangeiras participantes: Universidad Central de Venezuela, Universidad de Alicante, Universidad de Morón, Universidad Nacional de Mar del Plata, Universidade Aberta de Lisboa, Università degli studi di Roma "Tor Vergata”, Università degli Studi di Verona, University of London, Newcastle University e Universidade de Coimbra. 
deve ser sempre gratuita e cada vez mais apta a fomentar ensino, pesquisa e extensão de qualidade. Ainda que os números ajudem a produzir uma síntese do trabalho realizado nesse triênio e forneçam dados estatísticos para os planejamentos futuros, eles são incapazes de representar nosso contentamento pelo acolhimento da revista. A equipe da Hélade agradece os leitores, assim como aos autores dos artigos, que também possibilitam que este trabalho aconteça. Seguiremos com a mesma disposição. 